\title{
Paraplegia after celiac plexus neurolysis in a patient with pancreatic cancer - A case report and literature review -
}

Received March 13, 2018

Revised 1st, May 8, 2018

2nd, July 18, 2018

Accepted August 3, 2018

\section{Corresponding author}

Jae-hun Kim, M.D., Ph.D.

Department of Anesthesiology and

Pain Medicine, Konkuk University

School of Medicine, 120-1

Neungdong-ro, Gwangjin-gu, Seoul

05030, Korea

Tel: 82-2-2030-5470

Fax: 82-2-2030-5449

E-mail: painfree@kuh.ac.kr

\section{ORCID}

https://orcid.org/0000-0002-6774-1829

\section{Sung Hoon Kim, Kyung Hwan Jang, Bo Kyung Cheon, Jeong Ae Lim, Nam Sik Woo, Hae Kyung Kim, and Jae-hun Kim}

Department of Anesthesiology and Pain Medicine, Konkuk University School of Medicine, Seoul, Korea

\begin{abstract}
A 65-year-old male patient underwent C-arm fluoroscopy-guided bilateral celiac plexus neurolysis to relieve peritoneal seeding-related pain associated with pancreatic cancer. Following confirmation of spreading, and no intravascular injection of contrast media, $7.5 \mathrm{ml}$ of $0.25 \%$ chirocaine was injected in each side. The pain subsided after the block, with no motor or sensory deficits. Subsequently, celiac plexus neurolysis with $99.8 \%$ alcohol was performed using a posterolateral approach under fluoroscopic guidance. The patient was instructed to maintain a prone position for 2 hours while the procedure was performed. Approximately 4 hours later, the patient experienced paralysis of both lower extremities and hypoesthesia. Emergent magnetic resonance imaging of the thoracic and lumbar spine revealed gray matter signal change in the cord and conus medullaris at the T10-L1 level, and decreased perfusion at the T11-T12 vertebral bodies, suggesting spinal cord infarction. The patient remained paraplegic until his death 24 days later.
\end{abstract}

Keywords: Celiac plexus; Infarction; Pancreatic neoplasms; Paraplegia; Spinal cord.
Celiac plexus neurolysis (CPN) is an ablative procedure of the celiac plexus, which aims to destroy afferent pain-transmitting fibers from the abdominal viscera. $\mathrm{CPN}$ is a relatively safe procedure; it is associated with several relatively common and mostly transient complications, such as local pain (96\%), hypotension (10\%), and diarrhea (44\%) [1]. However, severe complications of CPN can include neurologic injuries such as paraplegia and anal and bladder sphincter dysfunction. Herein, we report a case of paraplegia by acute spinal cord infarction after CPN with alcohol.

\section{CASE REPORT}

A 65-year-old male patient (height, $166 \mathrm{~cm}$; weight, 69 $\mathrm{kg}$ ) was referred from the Department of Oncology for the management of epigastric pain caused by pancreatic cancer with peritoneal seeding. The patient had previously been treated for hypertension and diabetes. While undergoing 6 cycles of chemotherapy, he received dalteparin (10,000 IU) as treatment for pulmonary thromboembolism with deep vein thrombosis. For pain control, a $100 \mu \mathrm{g} / \mathrm{h}$ fentanyl patch was applied to the skin, and an average of $4 \mathrm{mg} / \mathrm{h}$ of morphine was administered intravenously. However, the patient complained of continuous pain (visual analog scale score 5/10; 0 = no pain, 10 = the most severe pain imaginable), so a C-arm fluoroscopic-guided CPN was performed. Before the procedure, the patient was fully informed of its potential complications.

The patient lay in the prone position while undergoing the C-arm fluoroscopic-guided bilateral CPN at the L1 level using

This is an Open Access article distributed under the terms of the Creative Commons Attribution Non-Commercial License (http://creativecommons.org/licenses/by-nc/4.0) which permits unrestricted non-commercial use, distribution, and reproduction in any medium, provided the original work is properly cited.

Copyright (c) the Korean Society of Anesthesiologists, 2019 
a posterolateral approach. A 21-gauge, 14-cm needle (Hakko, Japan) was inserted for the retrocrural approach of the celiac plexus block and placed at the posterior aorta in front of the vertebral body (Fig. 1). The proper location of the needle was confirmed by real-time imaging using a contrast agent, and no blood was aspirated when the needle was placed. Following confirmation of spreading near the aorta and no intravascular injection of contrast media (Fig. 2), 2-3 ml of contrast media was injected in each side. In each site, $0.5 \%$ chirocaine $(7.5 \mathrm{ml})$ was injected, and the optimal spreading of local anesthetics was confirmed by C-arm fluoroscopy. Approximately 15 minutes after the block, the patient's pain subsided, and no motor or sensory deficits were observed. Subsequently, 99.8\% alcohol ( $7 \mathrm{ml}$ ) was injected in each needle for additional neurolysis. After the procedure, the patient was instructed to maintain a prone position for 2 hours. Approximately 4 hours later, the patient noted paralysis of both his lower extremities, as well as hypoesthesia. A neurological examination also showed a decrease in sensory levels below the L1 dermatome. Thus, the patient was referred to a neurologist due to complete bilateral lower extremity and anal sphincter paralysis. Using emergent magnetic resonance imaging of the thoracic and lumbar spine, it was determined that there was a gray matter signal change in the cord and conus medullaris at the T10-L1 level, and decreased perfusion at the T11T12 vertebral bodies, suggesting a spinal cord infarction (Fig. 3). Prednisolone was injected with $1 \mathrm{~g}$ q every 24 hours for 3 days, followed by $60 \mathrm{mg}$ of prednisolone for 1 week which was then tapered down to $10 \mathrm{mg}$ for 1 week. High-dose steroids had no effect on our patient. The patient had complete pain relief following the procedure despite paraplegia. After 20 days, the amount of ascites had increased, and hypotension was aggravated. However, the patient and caregiver did not want any further treatment. A “Do Not Resuscitate” order was issued, and the patient died 4 days later.

\section{DISCUSSION}

A considerable number of cases of acute paraplegia after $\mathrm{CPN}$ have been reported for some time although it is rare. Paraplegia may occur when the nerve-destroying agent enters the subarachnoid or subdural space and directly impairs the spinal cord or somatosensory nerve [2]. Many authors report that damage to the Adamkiewicz artery by the needle or
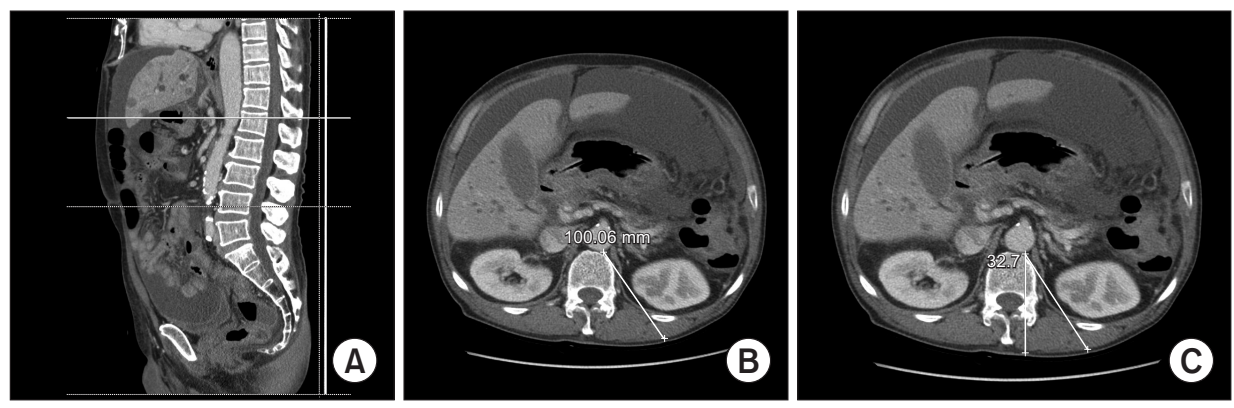

Fig. 1. The position of the transverse computed tomography $(\mathrm{CT})$ image at the L1 level (A), needle depth (B), and the angle of needle insertion to the target point $(\mathrm{C})$. We assessed the enhanced CT transverse images and selected the level without vessels connecting to the aorta for needle insertion.
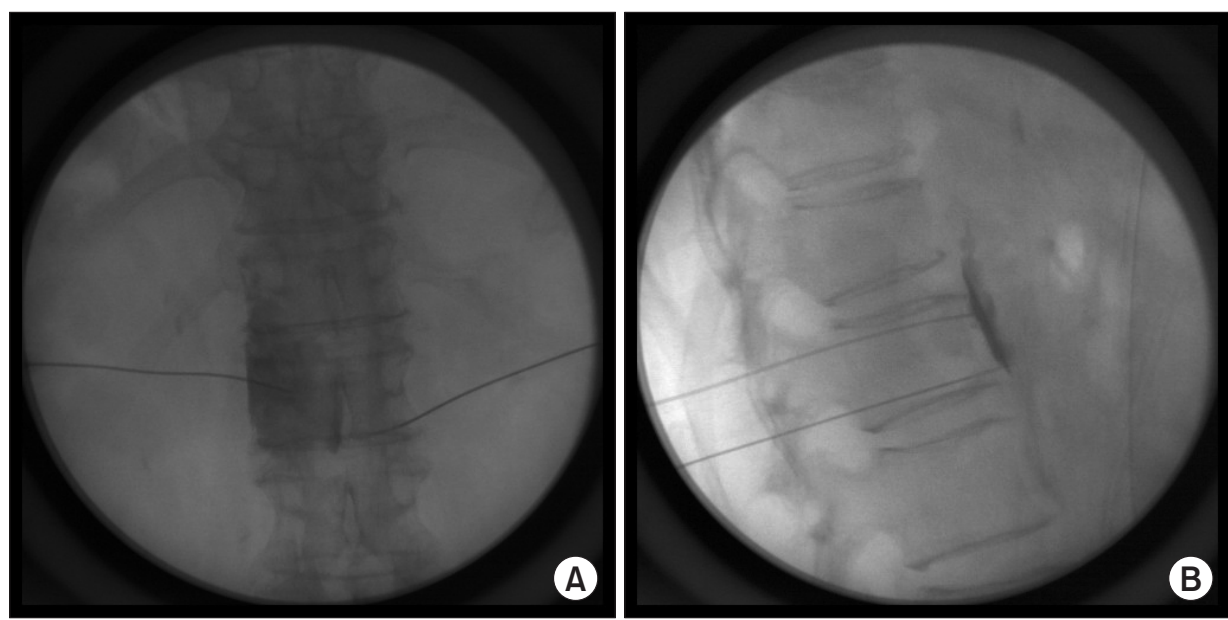

Fig. 2. The fluoroscopic anteroposterior (A) and lateral (B) view show the contrast medium spreading vertically over the 1st lumbar prevertebral space. 


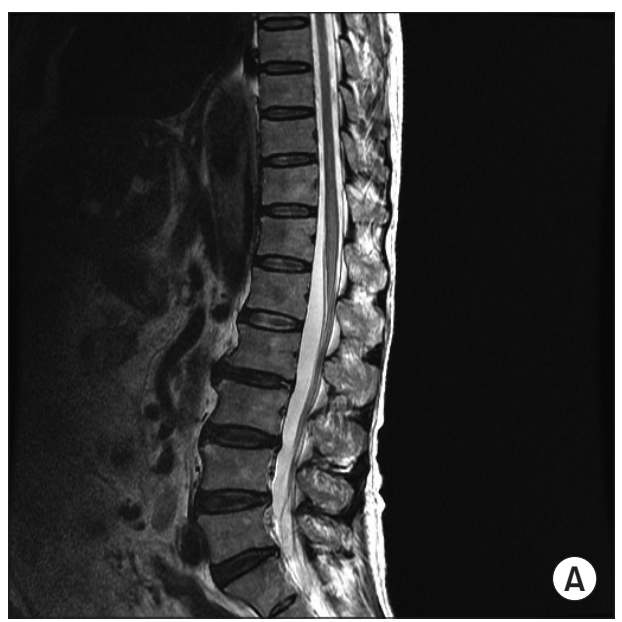

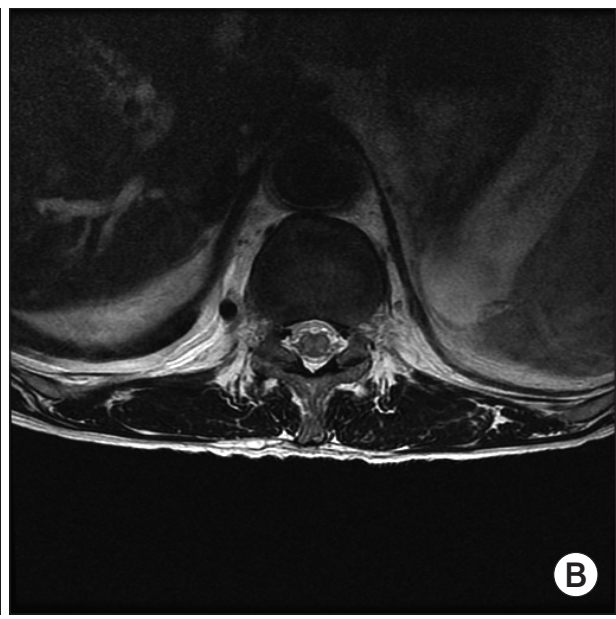

B
Fig. 3. T2-weighted sagittal (A) and transverse (B) magnetic resonance images show increased signal intensity in the spinal cord from the 10th thoracic to 1st lumbar level, suggesting the possibility of ischemic myelopathy. drug-induced vasospasm may result in spinal cord ischemia which can cause paraplegia. In this case, damage to the Adamkiewicz artery may not be the cause of paraplegia as there was no paraplegia or weakness for over 15 minutes after needle insertion before the injection of alcohol. We hypothesized that the cause of paraplegia may be alcohol spreading to the spinal cord or vasospasm due to the alcohol. In a case series of 2,730 CPN procedures, major complications of neurological deficits were limited to 4 cases $(<0.2 \%)$ [3]. All 4 cases had permanent paraplegia, while 3 of the 4 cases had loss of anal and bladder sphincter function as well. Alcohol (50-100\%) was used in all 4 cases.

Previously published articles on paraplegia after CPN are summarized in Table 1. In this case, the patient noted lower extremity paralysis with decreased sensory perception 4 hours after CPN. According to previous case reports, paraplegia can occur within 10-15 minutes of CPN [4-6]. In other cases, it was detected 1 or 3 hours later $[7,8]$. However, paraplegia can gradually develop over 2 days [9]. In some cases, it was difficult to detect the exact time of occurrence of paraplegia as the patient was under sedation [10,11]. Paralysis following a blind CPN was first reported by Galizia and Lahiri [4] in 1974. The blind procedure was performed, and the patient was symptomatic immediately after the injection of phenol on the left side suggesting a direct injury to the spinal cord or nerve rather than an arterial injury. With the exception of Galizia's article, most cases of paraplegia were reported with the use of alcohol. It is difficult to say whether paraplegia has a higher prevalence rate when using alcohol, rather than phenol, in CPN due to the lack of relative investigation. Although both alcohol and phenol are widely used for neurolysis, literature is scant on the relative effectiveness, duration of benefit, and complication profile of the two agents. No difference in pain outcomes was observed when comparing alcohol- and phenol-based splanchnic nerve neurolysis [12]. In a pilot study of phenol-based endoscopic ultrasoundguided CPN (EUS-CPN), phenol and ethanol had similar pain-relieving effects. Phenol, however, may be superior to ethanol in EUS-CPN procedures when comparing the incidence of inebriation and burning pain [13]. In an experiment conducted in dogs, the contractions of the segmental lumbar arteries caused by ethanol or phenol did not appear to be mediated through adrenergic, opioid, muscarinic, or serotonin receptors or sodium channels. The addition of procaine eliminated the sustained response of the vessel to ethanolinduced contraction, while this was not the case for phenolinduced contractions. It is possible that a concentration of phenol or alcohol leading to a contraction of these vessels could be achieved clinically [14]. They used 1\%, 3\%, 6\%, 7\%, $8 \%, 9 \%$ and $12 \%$ phenol and $3 \%, 6 \%, 10 \%, 25 \%, 50 \%, 75 \%$ and $90 \%$ ethanol. A high concentration of phenol, such as $8 \%, 9 \%$, $12 \%$, and low concentration of ethanol, such as $3 \%$ and $6 \%$, produced contractile responses. Therefore, a lower concentration of phenol and higher concentration of alcohol may be safe and limit vasospasms.

Until 2010, most cases of paraplegia after CPN were due to a percutaneous approach, with the exception of 2 cases of injection in the surgical field. After 2012, all 4 cases of paraplegia were from EUS-CPN. This may be due to the increased use of EUS-CPN, and the inability to confirm the intravascular injection during EUS-CPN. As shown in Table 1, $14(73.68 \%)$ of the 19 cases were permanent paraplegia, while 
Table 1. A Brief Summary of Published Articles

\begin{tabular}{|c|c|c|c|c|c|c|}
\hline Study & Year & Indication & Route & Paraplegia & Neurolytic agent & Other detail information \\
\hline Galizia [4] & 1974 & Cancer & PCN & Paraplegia & Phenol 6\% & $\begin{array}{l}\text { The Blind procedure, symptom was occurred } \\
\text { immediately after the injection of phenol on the } \\
\text { left side }\end{array}$ \\
\hline Leung [19] & 1983 & $\begin{array}{l}\text { Chronic } \\
\text { pancreatitis }\end{array}$ & PCN & Monoplegia only & Alcohol $75 \%$ & Left side monoplegia only \\
\hline Woodham [7] & 1989 & Cancer & PCN & Paraplegia & Alcohol 90\% & Alcohol was injected on the left only \\
\hline van Dongen [6] & 1991 & Cancer & PCN & Paraplegia & Alcohol 48\% & Under sedation \\
\hline Jabbal [8] & 1992 & Cancer & PCN & Reversible paraplegia & Alcohol 50\% & Right side dominant paraplegia \\
\hline $\mathrm{Na}[2]$ & 1993 & Cancer & PCN & Reversible paraplegia & Alcohol 50\% & $\begin{array}{l}30 \text { min after, burning sensation was occurred, } \\
\text { slowly progression of paraplegia }\end{array}$ \\
\hline \multirow[t]{4}{*}{ Davies [3] } & 1993 & $\begin{array}{l}\text { Chronic } \\
\text { pancreatitis }\end{array}$ & PCN & Paraplegia & Alcohol 66\% & Seven previous coeliac plexus blocks \\
\hline & & & PCN & Paraplegia & Alcohol 50\% & $\begin{array}{l}\text { Under general anaesthesia, patient moved with } \\
\text { injection }\end{array}$ \\
\hline & & $\begin{array}{l}\text { Chronic } \\
\text { pancreatitis }\end{array}$ & PCN & Paraplegia & Alcohol 90\% & Under sedation \\
\hline & & $\begin{array}{l}\text { Chronic } \\
\text { pancreatitis }\end{array}$ & PCN & Paraplegia & Alcohol $100 \%$ & Under general anaesthesia \\
\hline Wong [5] & 1995 & Cancer & $\mathrm{PCN}$ & Reversible paraplegia & Alcohol & $\begin{array}{l}\text { Transient paraplegia with anterior spinal artery } \\
\text { syndrome }\end{array}$ \\
\hline Kinoshita H & 1996 & Cancer & OP direct & Paraplegia & Alcohol & $\begin{array}{l}\text { Performed by open anterior approach under } \\
\text { direct vision }\end{array}$ \\
\hline Jun Hayakawa & 1997 & Cancer & Op direct & Paraplegia & Alcohol 99.5\% & $\begin{array}{l}\text { Performed by open anterior approach under } \\
\text { direct vision }\end{array}$ \\
\hline Kumar [18] & 2001 & Cancer & PCN & Reversible paraplegia & Alcohol & $\begin{array}{l}\text { Left side dominant paraplegia magnetic reso- } \\
\text { nance imaging and myelography were normal } \\
\text { Dorsal column pathways was spared }\end{array}$ \\
\hline Jeon [9] & 2010 & Cancer & PCN & Reversible paraplegia & Alcohol 99\% & Left side blood aspiration \\
\hline Fujii [10] & 2012 & Cancer & EUS & Paraplegia & Alcohol 99\% & $\begin{array}{l}\text { Under general anaesthesia anterior spinal cord } \\
\text { infarct }\end{array}$ \\
\hline Mittal [15] & 2012 & Cancer & EUS & Paraplegia & Alcohol 99\% & $\begin{array}{l}\text { Postprocedural computed tomography showed } \\
\text { that neurolytic/contrast agents were distributed } \\
\text { on both sides of the celiac trunk }\end{array}$ \\
\hline Minaga [11] & 2016 & Cancer & EUS & Paraplegia & Alcohol $100 \%$ & Under sedation \\
\hline Ibrahim & 2017 & Cancer & EUS & Paraplegia & Alcohol $100 \%$ & $\begin{array}{l}\text { Anterior spinal cord infarct, embolic occlusion of } \\
\text { Adamkiewicz arteries are detected }\end{array}$ \\
\hline
\end{tabular}

PCN: pancreatic cystic neoplasms, Op: operation, EUS: endoscopic ultrasound.

$5(26.32 \%)$ cases were reversible. Reversible lower extremity paralysis was first reported by Jabbal and Hunton [8] in 1992, where they assumed that the cause of paralysis was damage to the artery. However, no correlation between the position of the needle tip and the artery was found in this case due to the lack of a contrast agent.

The anatomy of the blood supply to the spinal cord is variable, and the major anterior radicular artery of Adamkiewicz is the largest of the anterior medullary feeders for the supply of the lower two-thirds of the spinal cord. In approximately $80 \%$ of cases, this artery appears on the left side between the $\mathrm{T} 7$ and L4 vertebral levels with a predilection for the T9 to T11 levels. Occasionally, this artery can be closely related to the celiac ganglion. The relative blood supply to the cord from the radicular arteries and the artery of Adamkiewicz varies considerably and depends on the degree of collateral circulation. Our patient's underlying diseases, such as hypertension and diabetes, would have caused poor collateral blood perfusion. Therefore, the spinal cord infarction was likely caused by weakening of the collaterals which could not maintain sufficient spinal cord perfusion once the major radicular artery was damaged during CPN. The mechanism of acute spinal cord ischemia after vascular puncture may involve vasospasm due to the high alcohol content (50-100\%) and high 
volume (20-50 ml) needle injury, causing acute thrombosis or the propagation of alcohol along segmental arteries leading to multiple artery spasms [15]. Preliminary data regarding radiofrequency ablation of splanchnic nerves are encouraging [16] and this method does not require neurolytic agents, such as alcohol and phenol. Even though further study is required to evaluate the safety of radiofrequency ablation of splanchnic nerves; theoretically, it could be considered an alternative choice to replace CPN with alcohol [16]. Furthermore, we hypothesize that eliminating the use of alcohol or phenol by splanchnic radiofrequency ablation could help prevent spinal cord ischemia due to vasoconstriction and damage caused by the direct injection of the drug into the subarachnoid or subdural space.

Paraplegia may occur when alcohol spreads to the subarachnoid or subdural space and directly damages the spinal cord or somatosensory nerve. If the spinal cord or somatosensory nerve is directly damaged, the patient may experience an abnormal sensation at the time of the procedure, or an immediate loss of muscle strength. In this case, the patient did not complain of burning pain or other symptoms after the alcohol injection. After this injection, the spreading within the anterior vertebral body area was limited as evidenced by C-arm fluoroscopy. Therefore, direct injection or spreading of alcohol to the epidural, subarachnoid, or subdural space may not have occurred in this case. We hypothesized that the position change after CPN could have caused alcohol to spread to another site or nerve. Therefore, we instructed the patient to maintain the prone position for 2 hours, eliminating the possibility of spreading the alcohol to other sites, such as the nerve root, subarachnoid, or subdural space. Some physicians instruct patients to maintain a prone position for over 2 hours after CPN [17]. However, we did not find studies examining the post-CPN position and maintaining time.

Of the 19 cases of paraplegia following CPN, 18 (94.74\%) were bilateral paraplegia while only $1(5.26 \%)$ case was monoplegia. Kumar et al. [18] reported left leg-dominant paraplegia, while Jabbal and Hunton [8] reported right sidedominant paraplegia. Leung et al. [19] reported left side monoplegia only. Jeon et al. [9] reported that blood was aspirated during the initial insertion of the left needle which may have caused spinal cord ischemia by puncturing the arterial structure. As spinal edema developed, progressive neurological deficits were noted, and the patient was thought to have progressively improved with the spinal edema. In a case described by Woodham and Hanna [7], the spread of the dye did not conform to the classical picture. They injected $90 \%$ alcohol ( $30 \mathrm{ml}$ ) on the left side, and $0.25 \%$ bupivacaine (20 $\mathrm{ml}$ ) on the right. As described above, the Adamkiewicz artery is likely located on the left side of the aorta, therefore, the possibility of spinal cord ischemia may be high when CPN is performed on the left side. As mentioned above, Jeon et al. [9] reported that blood was aspirated during the initial insertion of the left needle suggesting a need to be more careful when performing injections on the left side for CPN. The use of realtime radiography and digital subtraction angiography may help identify vascular injury more quickly. However, there were two cases of paraplegia of the lower extremities despite visualization of the CPN in the operation field. While the abdomen was open for the operation, the alcohol was injected posterior to the aorta at the level of the celiac plexus. Thus, even if the procedure is performed with caution, complications may occur due to anatomical variations in blood vessel location.

Although these fatal complications may occur after CPN, there is no doubt that CPN can reduce the side effects of opioids, as well as pain. This procedure also helps improve the quality of life of patients with terminal cancer. However, this procedure should be performed carefully in patients with benign disease like chronic pancreatitis due to the risk of serious complications. Furthermore, the use of radiofrequency ablation, rather than alcohol or phenol injection, should be further investigated for its potential to reduce spinal cord ischemia due to vasospasm and damage caused by direct injection of the alcohol into the subarachnoid or subdural space. Paraplegia has been considered a rare adverse effect of CPN, but is a very serious complication; therefore, pain physicians should always be aware of the risk of potentially serious consequences.

\section{CONFLICTS OF INTEREST}

No potential conflict of interest relevant to this article was reported.

\section{ORCID}

Sung Hoon Kim: https://orcid.org/0000-0002-0260-4858 
Kyung Hwan Jang: https://orcid.org/0000-0003-4883-6774

Bo Kyung Cheon: https://orcid.org/0000-0002-9731-4537

Jeong Ae Lim: https://orcid.org/0000-0003-4877-2969

Nam Sik Woo: https://orcid.org/0000-0002-2915-6354

Hae Kyung Kim: https://orcid.org/0000-0002-7193-6354

\section{REFERENCES}

1. Eisenberg E, Carr DB, Chalmers TC. Neurolytic celiac plexus block for treatment of cancer pain: a meta-analysis. Anesth Analg 1995; 80: 290-5.

2. Na AJ, Moon DE, Suh JH. Paraplegia following celiac plexus block: a case report. J Korean Pain Soc 1993; 6: 129-32.

3. Davies DD. Incidence of major complications of neurolytic coeliac plexus block. J R Soc Med 1993; 86: 264-6.

4. Galizia EJ, Lahiri SK. Paraplegia following coeliac plexus block with phenol. Case report. Br J Anaesth 1974; 46: 539-40.

5. Wong GY, Brown DL. Transient paraplegia following alcohol celiac plexus block. Reg Anesth 1995; 20: 352-5.

6. van Dongen RT, Crul BJ. Paraplegia following coeliac plexus block. Anaesthesia 1991; 46: 862-3.

7. Woodham MJ, Hanna MH. Paraplegia after coeliac plexus block. Anaesthesia 1989; 44: 487-9.

8. Jabbal SS, Hunton J. Reversible paraplegia following coeliac plexus block. Anaesthesia 1992; 47: 857-8.

9. Jeon SS, Moon DE, Ryu KH. A case of transient paraplegia following celiac plexus block with alcohol: a case report. Anesth Pain Med 2010; 5: 16-9.

10. Fujii L, Clain JE, Morris JM, Levy MJ. Anterior spinal cord infarction with permanent paralysis following endoscopic ultrasound celiac plexus neurolysis. Endoscopy 2012; 44 Suppl 2 UCTN: E265-6.

11. Minaga K, Kitano M, Imai H, Miyata T, Kudo M. Acute spinal cord infarction after EUS-guided celiac plexus neurolysis. Gastrointest Endosc 2016; 83: 1039-40.

12. Koyyalagunta D, Engle MP, Yu J, Feng L, Novy DM. The effectiveness of alcohol versus phenol based splanchnic nerve neurolysis for the treatment of intra-abdominal cancer pain. Pain Physician 2016; 19: 281-92.

13. Ishiwatari H, Hayashi T, Yoshida M, Ono M, Masuko H, Sato T, et al. Phenol-based endoscopic ultrasound-guided celiac plexus neurolysis for East Asian alcohol-intolerant upper gastrointestinal cancer patients: a pilot study. World J Gastroenterol 2014; 20 : 10512-7.

14. Brown DL, Rorie DK. Altered reactivity of isolated segmental lumbar arteries of dogs following exposure to ethanol and phenol. Pain 1994; 56: 139-43.

15. Mittal MK, Rabinstein AA, Wijdicks EF. Pearls \& oy-sters: acute spinal cord infarction following endoscopic ultrasound-guided celiac plexus neurolysis. Neurology 2012; 78: e57-9.

16. Garcea G, Thomasset S, Berry DP, Tordoff S. Percutaneous splanchnic nerve radiofrequency ablation for chronic abdominal pain. ANZ J Surg 2005; 75: 640-4.

17. Kim DH, Kim YC, Kim KH. Minimally invasive percutaneous spinal techniques. Philadelphia, Elsevier Saunders. 2010, p 175.

18. Kumar A, Tripathi SS, Dhar D, Bhattacharya A. A case of reversible paraparesis following celiac plexus block. Reg Anesth Pain Med 2001; 26: 75-8.

19. Leung JW, Bowen-Wright M, Aveling W, Shorvon PJ, Cotton PB. Coeliac plexus block for pain in pancreatic cancer and chronic pancreatitis. Br J Surg 1983; 70: 730-2. 